\title{
Hydrogen Peroxide in Upper Gastrointestinal Bleeding: A Coming of Age?
}

\author{
Anne Marie Lennon - Anthony N. Kalloo
}

Published online: 5 January 2010

(C) Springer Science+Business Media, LLC 2010

Acute upper gastrointestinal bleeding remains the most common medical emergency managed by gastroenterologists, with an incidence of 37-172 per 100,000 of the population per year. Despite advances in medical and endoscopic treatment, morality remains at between 3 and $14 \%$, rising to $33 \%$ for patients developing secondary upper gastrointestinal bleeding following admission for other reasons [1, 2]. Gastroduodenal ulcer disease is the commonest cause of upper gastrointestinal bleeding, accounting for almost $50 \%$ of admission caused by acute upper gastrointestinal bleeding, with 15,000 annual hospital admissions in the United States and an estimated cost of $\$ 750$ million [3, 4].

Several factors including advanced age, severe comorbidity, coagulopathy, hemodynamic instability, hematemesis, or hematochezia are predictors of recurrent bleeding. In addition, the appearance of gastric or duodenal ulcer base (Table 1) is one of the most important factors, and is used to predict the risk of rebleeding, determine prognosis, and the need for therapy [5-7]. Active hemorrhage and non-bleeding visible vessels within an ulcer are associated

This editorial refers to "Hydrogen peroxide $\left(\mathrm{H}_{2} \mathrm{O}_{2}\right)$ improves the visibility of ulcer bases in acute non-variceal upper gastrointestinal bleeding: a single-center prospective study" in the November 2009 issue of Digestive Diseases and Sciences, pages 2427-2433.

\section{A. M. Lennon}

The Johns Hopkins Hospital, 1830 East Monument Street, Room 431, Baltimore, MD 21205, USA

e-mail: amlennon@jhmi.edu

\section{A. N. Kalloo (凹)}

Division of Gastroenterology \& Hepatology, The Johns Hopkins

Hospital, Room 1m12, Cancer Research Building II,

1550 Orleans Street, Baltimore, MD 21231, USA

e-mail: akalloo@jhmi.edu with a high risk of rebleeding and necessitate endoscopic therapy [7]. Conversely, ulcers with a clean base or a flat spot rarely rebleed and can be managed medically, with early hospital discharge [8].

Ulcers with adherent clots have an intermediate risk of recurrent bleeding depending on the appearance of the ulcer base. The question of whether this group of patients should have medical treatment or aggressive removal of the clot followed by endoscopic therapy if appropriate was analyzed in a meta-analysis. The meta-analysis identified six randomized trials that included 240 patients, who were randomized to endoscopic clot removal and treatment or medical management [9]. Rebleeding occurred in $8.2 \%$ in the endoscopic therapy group and $24.7 \%$ in the medical group. The endoscopic features of an ulcer are therefore key in assessing risk and guiding subsequent management in patients who present with an upper gastrointestinal ulcer bleeding.

Several approaches have been used to improve visibility during upper gastrointestinal bleeding. Gastric lavage can be performed prior to or during endoscopy using a large diameter nasogastric tube [10]. Prokinetic agents have been used to improve gastric emptying and thus improve visibility. The most commonly used is erythromycin, a motilin agonist, which promotes rapid gastric emptying after intravenous injection. Its role in improving visibility has been examined in two prospective randomized, controlled studies which demonstrated improved quality of endoscopic examination and resulted in a reduced need for second-look endoscopy in the patients randomized to receive erythromycin ( $3 \mathrm{mg} / \mathrm{kg} / \mathrm{IV} \quad 20-60$ or $120 \mathrm{~min}$ before endoscopy) [11, 12]. Endoscopes with jumboinstrument channels, which allow the removal of blood and clot more efficiently, have also been used, however, these instruments have a larger diameter and generally have less 
Table 1 Forrest classification of stigmata of recent hemorrhage and associated re-bleeding rates [6]

\begin{tabular}{lll}
\hline Class & Endoscopic appearance & Re-bleeding rate (\%) \\
\hline Ia & Spurting arterial hemorrhage & $80-90$ \\
Ib & Oozing hemorrhage & $10-30$ \\
IIa & Non-bleeding visible vessel & $50-60$ \\
IIb & Adherent clot & $25-35$ \\
IIc & Black spot in ulcer base & $0-8$ \\
III & Clean ulcer base & $0-12$ \\
\hline
\end{tabular}

retroflexion capability. Vigorous lavage with a water pump, or removing the clot with a cold snare, suction, biopsy forceps or use of a thermal probe have also been described [13-16]. However, some of these modalities, such as cold snare clot removal, may precipitate bleeding.

Three percent hydrogen peroxide $\left(\mathrm{H}_{2} \mathrm{O}_{2}\right)$ has been available for several years as a topical antiseptic and disinfectant for oral administration as an antiseptic agent in mouth rinses and as a tooth whitener. The role of $\mathrm{H}_{2} \mathrm{O}_{2}$ in bleeding was first described in a canine model where it improved visualization in experimentally induced bleeding gastric ulcers [17]. A subsequent pilot study was performed in six patients with acute upper GI bleeding [18]. A blood clearance score (BCS; Table 2) was compared after flushing with water and then with $3 \% \mathrm{H}_{2} \mathrm{O}_{2}$. The six patients had minimal or no clearance of blood after flushing with water, however, there was a significant improvement in the BCS after flushing with $3 \% \mathrm{H}_{2} \mathrm{O}_{2}(p=0.03)$.

Three percent $\mathrm{H}_{2} \mathrm{O}_{2}$ improves visualization in upper gastrointestinal bleeding by altering the characteristics of blood, rendering it translucent and easier to remove. The mechanism by which $\mathrm{H}_{2} \mathrm{O}_{2}$ causes blood to become translucent is not known, but it is a powerful oxidizing agent and may damage the red cells, thereby causing hemolysis. Alternatively, catalase, which is present in all human red blood cells, causes degradation of $\mathrm{H}_{2} \mathrm{O}_{2}$, resulting in a rapid release of oxygen, which may increase mechanical trauma to red blood cells, promoting hemolysis. In addition, $\mathrm{H}_{2} \mathrm{O}_{2}$ may also have a hemostatic effect.

The article by Sridhar et al. [19] in the November 2009 issue of Digestive Diseases and Sciences, examined the effect of $3 \% \quad \mathrm{H}_{2} \mathrm{O}_{2}$ on ulcer visibility in patients with adherent clots in patients with acute non-variceal upper gastrointestinal bleeding. In this large, prospective, single-

Table 2 Blood clearance score (BCS) [18]

\begin{tabular}{ll}
\hline Grade & Description \\
\hline 0 & No change \\
1 & Minimal clearance \\
2 & Good clearance \\
3 & Excellent clearance \\
\hline
\end{tabular}

center study, all patients were administered intravenous proton pump inhibitor bolus followed by continuous infusion and underwent endoscopy within $6 \mathrm{~h}$ of admission. Prior to endoscopy, a gastric lavage was performed using $500 \mathrm{ml}$ of water. Patients with a clot present at endoscopy were eligible for inclusion in the study. In this group of patients, the base of the ulcer was sprayed with $250 \mathrm{ml}$ of water using a $5 \mathrm{Fr}$ spray tip catheter attached to a $30-\mathrm{ml}$ syringe. Adherent clots, defined as those resistant to targeted water spray, were sprayed with up to $100 \mathrm{ml}$ of $3 \%$ $\mathrm{H}_{2} \mathrm{O}_{2}$. The ulcer base was graded by the endoscopist using the BCS (Table 2) at the start of the procedure after the water lavage and following the application of $\mathrm{H}_{2} \mathrm{O}_{2}$. The change in the BCS after water and after $\mathrm{H}_{2} \mathrm{O}_{2}$ was also graded by a blinded reviewer on images taken during the procedure.

Three hundred and twenty patients were screened, of whom 81 were eligible for inclusion in the study with adherent clots. The mean BCS visual score decreased from 0.06 before water application, to 0.78 after water application, and 2.83 after $\mathrm{H}_{2} \mathrm{O}_{2}$, with a significant improvement in the score $(2.04 ; 95 \%$ CI 1.86-2.23) following application of $\mathrm{H}_{2} \mathrm{O}_{2}$. This was highly significant $(p=0.00)$, improving visibility in both gastric $(n=34)$ and duodenal ulcers $(n=47)$.

Lower volumes of $\mathrm{H}_{2} \mathrm{O}_{2}$ were required (33 and $35 \mathrm{ml}$ ) for patients with duodenal or gastric ulcer on NSAIDS $(n=40)$, compared to those not taking NSAIDS (45 and $56 \mathrm{ml}$, respectively). The authors hypothesized that this may be because the clot is less stable due to platelet dysfunction. Importantly, no patient suffered any side-effects during a 1-month follow up.

There are some limitations of this study. It is a nonrandomized, non-placebo-controlled, single-center study. A potential confounding factor is the degree of vigor and method with which clots were irrigated, as gentle irrigation with a syringe may fail to expose the underlying stigmata. None of the patients in this study had clearance of the clot after water irrigation. This contrasts with a study by Laine et al. [13] who used a 3.2-mm bipolar probe to irrigate for up to $5 \mathrm{~min}$, where only $57 \%$ of patients had clot remaining. Another study by Lin et al. [16] compared irrigation with a syringe with a water jet. Clots were removed using syringe irrigation in only $9 \%$ of 165 patients, whereas clots were removed in an additional $26 \%$ of patients with the water jet [16].

The BCS score is subjective and the primary endoscopist was not blinded, which could be associated with observer bias. The authors examined the intra-observer and inter-observer agreement for the BCS score. The interobserver agreement on the BCS score between the endoscopist and the blinded observer was good with a kappa of 0.78 (95\% CI $0.50-1.0 ; p=0.001$ ) before water, 0.80 
(95\% CI 0.70-0.92; $p 0.001)$ after water and 0.75 (CI $0.57-$ $0.94 ; p$ 0.001) after $\mathrm{H}_{2} \mathrm{O}_{2}$. The intra-observer value was also good with kappa score of 0.64 (95\% CI 0.32-0.97) before water, 0.82 (95\% CI 0.72-0.93) after water and 0.74 (95\% CI 0.55-0.94) after $\mathrm{H}_{2} \mathrm{O}_{2}$, suggesting that the BCS score is reproducible and is a valid scoring method.

Helicobacter pylori infection was determined by the rapid urease test taken at the time of the upper endoscopy, which may have underestimated the number of patients infected. An important note in this study is that patients with clots larger than $2 \mathrm{~cm}$ were excluded from the study. The authors excluded this group as they had previously found $\mathrm{H}_{2} \mathrm{O}_{2}$ was ineffective in this group.

Despite these limitations, this study clearly demonstrates the usefulness of $\mathrm{H}_{2} \mathrm{O}_{2}$ in allowing visualization of the ulcer base in patients with adherent clot less than $2 \mathrm{~cm}$. $\mathrm{H}_{2} \mathrm{O}_{2}$ should be considered in all patients with non-visible ulcer base.

\section{References}

1. van Leerdam ME, Tytgat GN. Acute gastrointestinal bleeding. Best Pract Res Clin Gastroenterol. 2008;22(2):207-208.

2. Rockall TA, Logan RF, Devlin HB, et al. Incidence of and mortality from acute upper gastrointestinal haemorrhage in the United Kingdom. Steering Committee and members of the National Audit of Acute Upper Gastrointestinal Haemorrhage. BMJ. 1995;311(6999):222-226.

3. Silverstein FE, Gilbert DA, Tedesco FJ, et al. The national ASGE survey on upper gastrointestinal bleeding. II. Clinical prognostic factors. Gastrointest Endosc. 1981;27(2):80-93.

4. Jiranek GC, Kozarek RA. A cost-effective approach to the patient with peptic ulcer bleeding. Surg Clin North Am. 1996;76(1): 83-103.

5. Hay JA, Lyubashevsky E, Elashoff J, et al. Upper gastrointestinal hemorrhage clinical-guideline determining the optimal hospital length of stay. Am J Med. 1996;100(3):313-322.

6. Forrest JA, Finlayson ND, Shearman DJ. Endoscopy in gastrointestinal bleeding. Lancet. 1974;2(7877):394-397.
7. Rockall TA, Logan RF, Devlin HB, et al. Risk assessment after acute upper gastrointestinal haemorrhage. Gut. 1996;38(3):316-321.

8. Cipolletta L, Bianco MA, Rotondano G, et al. Outpatient management for low-risk nonvariceal upper GI bleeding: a randomized controlled trial. Gastrointest Endosc. 2002;55(1):1-5.

9. Kahi CJ, Jensen DM, Sung JJ, et al. Endoscopic therapy versus medical therapy for bleeding peptic ulcer with adherent clot: a meta-analysis. Gastroenterology. 2005;129(3):855-862.

10. Oksuzoglu G, Kadayifci A, Arslan M, et al. Coping with severe upper gastrointestinal bleeding: nasogastric tube and endoscope used together. Endoscopy. 1996;28(8):725-726.

11. Frossard JL, Spahr L, Queneau PE, et al. Erythromycin intravenous bolus infusion in acute upper gastrointestinal bleeding: a randomized, controlled, double-blind trial. Gastroenterology. 2002;123(1):17-23.

12. Coffin B, Pocard M, Panis Y, et al. Erythromycin improves the quality of EGD in patients with acute upper GI bleeding: a randomized controlled study. Gastrointest Endosc. 2002;56(2): 174-179.

13. Laine L, Stein C, Sharma V. A prospective outcome study of patients with clot in an ulcer and the effect of irrigation. Gastrointest Endosc. 1996;43((2 Pt 1)):107-110.

14. Jensen DM, Kovacs TO, Jutabha R, et al. Randomized trial of medical or endoscopic therapy to prevent recurrent ulcer hemorrhage in patients with adherent clots. Gastroenterology. 2002; 123(2):407-413.

15. Bleau BL, Gostout CJ, Sherman KE, et al. Recurrent bleeding from peptic ulcer associated with adherent clot: a randomized study comparing endoscopic treatment with medical therapy. Gastrointest Endosc. 2002;56(1):1-6.

16. Lin HJ, Wang K, Perng CL, et al. Natural history of bleeding peptic ulcers with a tightly adherent blood clot: a prospective observation. Gastrointest Endosc. 1996;43(5):470-473.

17. Kalloo AN, Hill S, Wadwa K, et al. The utility of hydrogen peroxide in the management of acute gastrointestinal bleeding (AGIB) in a canine model: a placebo-controlled randomized trial. Am J Gastroenterol. 1996;43:297.

18. Kalloo AN, Canto MI, Wadwa KS, et al. Clinical usefulness of $3 \%$ hydrogen peroxide in acute upper GI bleeding: a pilot study. Gastrointest Endosc. 1999;49((4 Pt 1)):518-521.

19. Sridhar S, Chamberlain S, Thiruvaiyaru D, et al. Hydrogen peroxide improves the visibility of ulcer bases in acute non-variceal upper gastrointestinal bleeding: a single-center prospective study. Dig Dis Sci. 2009;54(11):2427-2433. 